\title{
Abordagem ao adolescente e ao jovem nas políticas públicas de saúde no Brasil: um estudo de revisão
}

\author{
| ${ }^{1}$ Natália de Cássia Horta, ${ }^{2}$ Roseni Rosângela de Sena |
}

Resumo: Este artigo teve como objetivo analisar a abordagem e a concepção de adolescente e jovem presentes nos documentos oficiais de saúde publicados pelo Ministério da Saúde, bem como a organização da atenção à saúde proposta para esses sujeitos. Além disso, objetivou contrapor, comparar e relacionar os documentos oficiais com as experiências e pesquisas publicadas nas bases selecionadas, buscando propor estratégias de aperfeiçoamento para as políticas de saúde atuais. Estudo de abordagem exploratória e descritiva, com caráter documental, realizado por meio de revisão de documentos oficiais publicados pelo Ministério da Saúde e de artigos disponíveis em bases científicas selecionadas. Por meio da análise de conteúdo e da estruturação de três categorias analíticas, os dados foram discutidos considerando: a concepção de adolescência e juventude; a perspectiva das políticas públicas para os jovens; e a análise do processo saúde-doença na juventude versus as práticas de saúde. Como resultado, foi possível identificar que a abordagem do setor saúde centra-se no conceito de adolescência, numa perspectiva do risco, com pouco enfoque para a juventude, o que tem repercussão nas políticas públicas estruturadas.

$\mathrm{Na}$ área da saúde, as publicações analisadas evidenciam a compreensão do processo saúde-doença de forma fragmentada, com pouca repercussão para uma atenção integral à saúde dos jovens. As evidências deste estudo apontam para a necessidade de integração da saúde com outras políticas voltadas para os jovens, a necessidade de diálogo com as produções acadêmicas sobre juventude para a melhoria das ações ofertadas a essa população e a incorporação desse referencial na área da saúde.

> Palavras-chave: políticas públicas; adolescência; juventude; processo saúde-doença; saúde do adolescente; enfermagem.
1 Graduação em Enfermagem
pela Universidade Federal
de Minas Gerais (2004).
Mestrado em Enfermagem
pela Universidade Federal de
Minas Gerais. Atualmente é
professora Assistente III da
Pontifícia Universidade Católica
de Minas Gerais e doutoranda
pela Escola de Enfermagem da
UFMG. Endereço eletrônico:
nanahorta@yahoo.com.br
2 Enfermeira. Doutora em
Enfermagem. Coordenadora do
Núcleo de Estudos e Pesquisas
sobre Ensino e Práticas de
Enfermagem da Escola de
Enfermagem da UFMG.
Professora Emérita da Escola de
Enfermagem da Universidade
Federal de Minas Gerais.
Pesquisadora Nível 1 do CNPQ.

Enviado em: 13/02/2010. Aprovado em: 05/05/2010. 
Os adolescentes e jovens, na faixa etária compreendida entre 10 e 24 anos, representam $29 \%$ da população mundial, sendo que $80 \%$ vivem em países em desenvolvimento como o Brasil (BRASIL, 2008). Os adolescentes e jovens correspondem a $30,33 \%$ da população brasileira, ou seja, $1 / 3$ da população total, o que faz com que o Brasil seja um país de população relativamente jovem (IBGE, 2007). A partir da segunda metade da década de 1990, tem-se, no Brasil, o alargamento da pirâmide etária na adolescência e juventude, compreendida entre 10 e 24 anos. Os efeitos desse fenômeno, como em ondas sucessivas, serão sentidos nas faixas etárias subsequentes, a cada década, e resultam no aumento absoluto da população que vai se integrando às faixas etárias seguintes, fenômeno denominado de onda jovem. A queda da fecundidade, o crescente declínio da mortalidade infantil e o aumento da esperança de vida ao nascer são fatores que contribuem para a ocorrência dessa onda, merecendo destaque um ligeiro decréscimo populacional de jovens na faixa etária compreendida entre 20 e 24 anos. Esse declínio está atribuído à mortalidade por causas externas e contribui para a configuração do cenário de morbi-mortalidade da população adolescente e jovem no Brasil. Os acidentes e homicídios, sobretudo relacionados ao tráfico de drogas e uso abusivo de álcool e as intercorrências da gravidez e maternidade são as principais causas-base desse panorama (BORGES; FUJIMORI, 2009).

Considerando as alterações demográficas, é fundamental elaborar estratégias públicas que focalizem a saúde dessa população com ações promotoras da saúde, preventivas e curativas, capazes de garantir a assistência integral à saúde dos jovens. Além disso, são sujeitos sociais com grande potencial de mobilização e de mudança.

Grossman e Cardoso (1997, p. 1) afirmam que "os documentos oficiais de atenção à saúde dos adolescentes são fontes privilegiadas para o entendimento de como e por que a sociedade operacionaliza a saúde como instrumento de conhecimento, administração e controle do futuro". Historicamente, as concepções veiculadas na área da saúde, em particular, tendem a universalizar/naturalizar/ padronizar o processo vivenciado na adolescência e juventude, segundo parâmetros preestabelecidos, desconsiderando os fatos vividos e significados que marcam o processo de individualização de sujeitos concretos, assim como as possibilidades 
diferenciais e desiguais que a sociedade cria para as vivências nesse período (PERES, 1998). Horta, Lage e Sena (2009), em estudo de revisão, afirmam que há apropriação do conceito de juventude pelas Ciências Humanas e Sociais, diferentemente das Ciências da Saúde, que se atêm ao conceito de adolescência como fase de transição e com foco nos aspectos biológicos, na abordagem dos riscos e da vulnerabilidade desse grupo etário. Correa (2006) coloca que os estudos produzidos na saúde, especificamente na enfermagem, tendem a homogeneizar a definição de adolescência, se atendo a limites cronológicos na definição do termo. Afirma também que as políticas de saúde, na atualidade, são implementadas segundo o modelo médico vigente, sendo determinadas por "pacotes fechados", de forma a atenderem à população de maneira unificada, descaracterizando suas necessidades específicas e suas subjetividades, o que, com relação à saúde dos adolescentes, mostra-se insuficiente. Essas ações tendem a ofertar práticas que são, tradicionalmente, medicalizadoras das necessidades, mesmo que estejam para além do âmbito biológico, como os aspectos sociais e culturais que são, em muitas situações, banalizados.

Comopolíticaspúblicas, Sposito(2003b,p.59)afirmaqueessetermo “compreende a dimensão ético-política dos fins da ação e deve-se aliar, necessariamente, a um projeto de desenvolvimento econômico-social e implicar formas de relação do Estado com a sociedade". Envolvendo atores e objetivos diferenciados, é importante considerar também que a construção de políticas públicas se dá por um processo de conflitos e disputa de interesses e recursos disponíveis na sociedade. A construção dessas políticas é a operacionalização do biopoder, compreendido como os mecanismos empregados para controlar a população e disciplinar indivíduos e das biopolíticas, como um dos polos do biopoder, e que emprega os controles e intervenções reguladoras para manejar a população e, por isso, carregam consigo tensōes e impasses (FOUCAULT, 2004).

Desse modo, este estudo teve como objetivo analisar a abordagem e a concepção de adolescente e jovem presentes nos documentos oficiais de saúde publicados pelo Ministério da Saúde, bem como a organização da atenção à saúde proposta para esses sujeitos. Além disso, objetivou contrapor, comparar e relacionar os documentos oficiais com as experiências e pesquisas implementadas e publicadas nas bases selecionadas, buscando propor estratégias de aperfeiçoamento para as políticas de saúde atuais. 
A justificativa para a estruturação dessa produção remete à necessidade de contextualização política da temática da adolescência e juventude no cenário nacional, como forma de analisar o discurso e as práticas institucionais e confrontá-los com a produção atual sobre a temática.

\section{Metodologia}

Trata-se de estudo de abordagem exploratória e descritiva com caráter documental, construído a partir de revisão de publicações do Ministério da Saúde referentes à temática da adolescência e juventude. As publicações foram recuperadas por consulta à Biblioteca Virtual em Saúde do Ministério da Saúde, a partir dos descritores adolescência e juventude.

Foram analisadas 12 publicações compreendidas entre 1989 e 2008, considerando-se aquelas disponíveis como textos completos e publicados exclusivamente pelo Ministério da Saúde. Buscou-se construir uma análise das açōes propostas, enfocando a conceituação de adolescência e juventude, a compreensão do processo saúde-doença e a organização para a atenção à saúde do adolescente e do jovem, propostas nessas publicaçōes.

Para embasar a discussão das publicações do Ministério da Saúde selecionadas, foram recuperados 43 artigos de periódicos indexados nas bases LILACS e SCIELO, compreendidos entre os anos de 2004 e 2009, que tinham como foco as políticas públicas para adolescentes e jovens de forma geral, os programas oriundos dessas políticas ou que sinalizam possibilidades de avanços em sua construção. A busca dos artigos foi feita por meio de associação do descritor "políticas públicas" com os descritores "adolescência" e "juventude". Destaca-se que foram recuperados todos os artigos disponibilizados na busca, não sendo eliminada, a priori, nenhuma das publicações.

Ao relacionar os descritores de "políticas públicas" e "juventude", foram recuperados cinco artigos na base SciELO e 16 artigos na base LILACS. Associando-se os descritores políticas públicas e adolescência, foi possível recuperar seis artigos no SciELO e 16 artigos na base LILACS, destacando que foram similares àqueles recuperados na associação com o descritor "juventude”. Constituíram-se objeto deste estudo todas as referências de artigos identificadas nas bases selecionadas e disponibilizadas na íntegra, sendo excluídas as teses, manuais, livros e artigos repetidos nas bases. 
Ao final da seleção de bibliografias, constituiu-se como objeto de análise deste estudo o total de 28 publicações sendo 12 documentos oficiais do Ministério da Saúde e 16 artigos que possibilitaram construir a reflexão proposta. Por meio da análise de conteúdo das publicações e da estruturação de três categorias analíticas, a discussão contempla a concepção de adolescência e juventude; a perspectiva das políticas públicas para os jovens; e a análise do processo saúde-doença na adolescência e juventude versus práticas de saúde. A interpretação dos dados foi fundamentada em outros autores de referência sobre a temática da adolescência e juventude.

Destaca-se que os artigos selecionados abordavam pesquisas, relatos de experiências e reflexões sobre políticas públicas em diferentes áreas, como na área social, de educação, de direito e cultura, apontadas, na literatura, como as que concentram a maior parte dos programas oriundos de políticas públicas em nível federal. Destaca-se a importância de fazer dialogar e articular os programas oriundos das políticas de saúde com essas outras áreas, tendo em vista a interface de se direcionarem ao mesmo público, com possibilidade de ações transversais capazes de trazer inovações e repercussões importantes para essa população.

\section{Resultados e discussão dos dados}

\section{Concepção de adolescência e juventude}

$\mathrm{Na}$ análise das publicações selecionadas, foi possível perceber que a conceituação prevalente, nos documentos oficiais do Ministério da Saúde, é de adolescência, marcada por uma delimitação etária de 10 a 19 anos e vinculada às transformações físicas, ao crescimento e desenvolvimento e à maturação sexual (BRASIL, 1989 e 1993). Centram-se também nos aspectos referentes aos riscos atribuídos aos adolescentes pela curiosidade e experimentação vivenciados nessa fase.

A concepção de juventude é apontada, nos documentos oficiais, a partir da instituição, em 1999, da Área de Saúde do Adolescente e do Jovem, da Secretaria de Políticas de Saúde do Ministério da Saúde, compreendendo o limite etário de 15 a 24 anos. O discurso oficial enfatiza a necessidade de se perceber a adolescência e juventude com limites etários compreendendo adolescentes de 10 a 14 anos, adolescentes jovens de 15 a 19 anos e adultos jovens de 20 a 24 anos, sendo as ações de saúde, a partir de então, destinadas às faixas etárias de 10 a 24 anos. Amarante e Soares (2009) afirmam que é ainda mais recente a incorporação de referenciais de juventude na elaboração de políticas públicas 
no Brasil, sendo mais prevalente a partir de 2003, com a criação da Secretaria Nacional de Juventude. Considera-se que o discurso, a partir daí, define uma perspectiva de compreensão dessa população, não mais apenas como geradora de problemas que afligem mas, também, como um grupo de indivíduos que se desenvolve com energia, espírito criativo, inovador, construtivo e com potencial de contribuição para o desenvolvimento do país (BRASIL, 1999).

Segundo Rocha (2005), perceber os jovens como um problema sinaliza para uma significativa preocupação, uma vez que, com isso, teríamos um grande problema "formado por 33 milhôes de cidadãos na faixa de 15 a 24 anos. No entanto, se os vemos como pessoas cheias de ideias, questionamentos, propostas e dificuldades como todos nós, temos um terreno fértil e vasto pela frente”.

Desse modo, o cenário atual aponta para a necessidade de problematização dos conceitos de adolescência e juventude. Tomadas como sinônimos na área da saúde, principalmente nos campos da psicologia, enfermagem e medicina, e como categoria supostamente homogênea pelas políticas públicas, essa imprecisão conceitual acaba por obscurecer as práticas sócio-políticas para esse grupo do que esclarecê-las. Até mesmo nas bases científicas da saúde, os conceitos de adolescência e juventude aparecem como sinônimos. Aqui, vale destacar a crítica ao fato de que, até mesmo como descritores nas bases indexadas para a busca de publicações, a imprecisão conceitual é certificada.

Considerar os contextos de vida, as particularidades, os recursos existentes e acionados é fundamental na conceituação e na compreensão da adolescência e juventude. Nas classes sociais mais privilegiadas, a adolescência e juventude tendem a se estender, enquanto que, nas periferias, a vivência da juventude é encurtada pelas necessidades de que os jovens assumam o trabalho além da família, com a chegada dos filhos, marcadores da vida adulta.

A noção de juventude, antes definida com base em marcos etários, adquire importância no correr do século XX e se refere principalmente ao período "marcado por ambivalências, pela convivência contraditória de elementos de emancipação e subordinação, sempre em choque e negociação", durante o qual o sujeito elabora seu próprio amadurecimento (NOVAES; VANUCCHI, 2004, p. 12). A juventude, então, merece ser entendida como uma construção social que se distancia da concepção de adolescência apegada às modificaçôes biológicas e à puberdade (ROCHA, 2005). 
Percebe-se, desse modo, a imprecisão conceitual de adolescência e juventude na área da saúde partindo, primeiramente, da arbitrariedade na demarcação do limite etário. No bojo das diversas políticas de Estado, há aquelas que levam em conta o limite trazido pelo Estatuto da Criança e do Adolescente de 12 a 18 anos, o do Conselho Nacional da Juventude de 15 a 29 anos, além daqueles propostos pelas organizações internacionais que, ora estendem e ora limitam, a adolescência e a juventude. É importante considerar que o uso da faixa etária para estabelecer limites de uma fase da vida é arbitrário, também por correr o risco de que, dessa forma, sejam ignorados os contextos sociais e culturais, considerando que as fronteiras entre idades pelas quais os indivíduos passam não são necessariamente as mesmas em todas as sociedades (DEBERT, 2003). Mesmo considerando importantes essas definições no que se refere à estruturação das políticas públicas, deve-se levar em conta as repercussões que esses limites trazem no que se refere às açôes e metodologias dos programas definidos como políticas e que trazem impactos na vida dos jovens.

Vilella e Doreto (2006) afirmam que, para alguns autores, a adolescência traria o sentido etário, enquanto a juventude traria um sentido geracional; a juventude tem um sentido coletivo que remete a um segmento populacional de uma sociedade, ao passo que a adolescência está mais relacionada ao plano individual, demarcado cronologicamente. Com base na delimitação etária, Sposito, Carvalho e Silva e Sousa (2006) afirmam um predomínio de ações oriundas de programas no cenário brasileiro voltadas para adolescentes de $14 \mathrm{a}$ 17 anos, quando comparadas com programas híbridos quanto às faixas etárias dos jovens de 15 a 29 anos. As autoras apontam que a análise dessas ações pelo Estado merece atenção especial, uma vez que implica não só um alargamento da temporalidade do ciclo de vida, mas também a verificação de como as possíveis divisões etárias desse contingente levam em conta o maior número de afinidades do que de dissonâncias. Buscando reunir adolescentes e jovens em um mesmo programa como uma ação mais adequada do que trazer os adolescentes para o universo da infância, as autoras apontam outras implicações, quando se remete aos marcos legais da maioridade que são arbitrários, produto de consensos provisórios, e não deveriam implicar restrição da ação do Estado, pois deixam à sombra categorias significativas de jovens sobre as quais o Poder Público, no Brasil, não assume qualquer responsabilidade. 
A compreensão da adolescência e juventude, apontada na literatura selecionada, explicita outros elementos importantes a serem considerados para a abordagem dessa população. Tem-se, com isso, a necessidade de se atentar para as vivências, as especificidades e os diversos modos de adolescer e de ser jovem no Brasil que geram experiências plurais a esses sujeitos. Para Orlandi e Toneli (2008, p. 318), adolescência e juventude "são significadas de maneiras diversas nas culturas que as designam, bem como em meio a cada grupo, sendo, em última instância, particularizadas em cada sujeito, em vista da singularidade do processo de constituição de cada um".

Desse modo, a compreensão da condição e da situação juvenil se faz cada vez mais necessária na estruturação de políticas, em especial na área da saúde, ao se remeter aos elementos complexos que estruturam o conceito de saúde como sendo produto do bem-estar que envolve a interação e determinação pelo meio-social, pelo meio ambiente e com os recursos e possibilidades para viver de cada sujeito.

Mesmo sendo apontada em documentos oficiais mais recentes da Saúde, a percepção de adolescência como um conceito plural, na perspectiva de adolescências (BRASIL, 2002), e considerando-se também os componentes biológicos, emocionais e socioculturais que permeiam esse momento específico da vida, ainda é possível avançar na concepção de "adolescências" e "juventudes” na área da saúde. A forma como percebemos esses sujeitos tem repercussão direta na estruturação das ações que os envolvem. Se os órgãos oficiais os veem como risco, as ações são, em geral, compensatórias e mais corretivas. Se vistos como problema social e como transgressores, as ações tendem a ser de oferta de soluções estruturadas por adultos, sem propiciar a escuta desses sujeitos e sem considerá-los como sujeitos de suas vidas, com o risco de nos esquecermos de atentar para a complexidade das situações que produzem e/ou fortalecem essas situaçōes (ROCHA, 2005).

Com base nessa compreensão, apresenta-se-nos a necessidade de avançar para uma construção com os jovens e em que esses não sejam tomados como problemas frente aos quais devem debruçar-se os esforços de reintegração social. Entendido assim, o tempo livre do jovem é tido como perigoso, devendo o jovem ser sempre ocupado com práticas apontadas pelos discursos oficiais como necessárias, como a capacitação profissional, os projetos de transferência de renda, entre outras, veladas por um discurso de protagonismo juvenil (RAUPP; MILNITSKY-SAPIRO, 2005). A perspectiva de mudança não se concretiza no âmbito de alteração da nomenclatura adotada tradicionalmente pelo setor 
saúde, mas sim, embasada por um diferencial na concepção de ser jovem na contemporaneidade, considerando a juventude como categoria relacional tendo como base a heterogeneidade e a diversidade da condição juvenil.

\section{A perspectiva das políticas públicas para os jovens}

A (in)definição conceitual de adolescência e juventude traz repercussões importantes na estruturação de políticas públicas para essa população. Nesse sentido, Spósito et al. (2006, p. 255) afirmam que "a ideia de adolescência carrega, não só estigmas de natureza psicológica ou patológica, tradicionais em algumas teorias facilmente absorvidas pelo senso comum, como incorpora o estereótipo que designa aqueles que ameaçam a sociedade”. A juventude, para esses autores, vem atrelada a discursos que buscam construir acepções capazes de propor uma maior positividade na imagem dos segmentos juvenis mas restam dissociados das práticas destinadas aos "vulneráveis".

Considerando o significativo número de adolescentes e jovens no cenário brasileiro e seu não-lugar social, tem-se um longo e importante caminho a ser percorrido na implementação de políticas públicas para essa população. Nesse sentido, Oliveira e Milnitsky-Sapiro (2007) destacam que a produção acadêmica, aliada à produção técnica, pode contribuir nesse processo, especialmente no que se refere ao reconhecimento do lugar do adolescente na sociedade o que, para Spósito; Carvalho e Silva e Sousa (2006), traz repercussões importantes, já que a conformação das políticas e programas públicos não sofre apenas os efeitos de concepções, mas pode provocar modulações nas imagens dominantes que a sociedade constrói sobre seus sujeitos jovens.

Apresenta-se, aqui, uma breve análise de aspectos apontados, na revisão feita neste artigo, sobre as políticas públicas para adolescentes e jovens de forma geral. No período compreendido entre 1999 e 2002 houve, no Brasil, aumento significativo das políticas referentes à temática dos adolescentes e jovens no âmbito do Governo Federal, quando comparado aos anos anteriores à década de 1990. Esse fato não permite afirmar a construção de um novo caminho, já que se constata que o salto qualitativo desses projetos foi pequeno, quando se analisa o desenho institucional mínimo na conformação de uma unidade nessa construção. Trata-se, portanto, de projetos isolados que não sinalizam na direção da consolidação de políticas e formas democráticas de gestão (SPÓSITO, 2003). 
Brito (2005) aponta que as políticas públicas de juventude começam a ganhar espaço público, à medida que surgem projetos e programas que buscam enfrentar dois grandes problemas indicados pelos jovens: a violência e o desemprego. Aponta ainda para a ausência de espaços de escuta dos jovens na construção das políticas que, pelo menos em suas fases de implementação e desenvolvimento, deveriam contar com participação direta e efetiva dos jovens.

A partir de 2003, tem-se instalado um campo de discussão de políticas públicas para os jovens, ao lado da instituição da Secretaria Nacional de Juventude e do Conselho Nacional de Juventude, que podem, segundo as autoras, não refletir necessariamente em mudanças significativas no interior de uma agenda pública que tem a juventude e seus direitos como tema (SPÓSITO; CORROCHANO, 2005). A polêmica remete à avaliação da necessidade de uma política específica para a juventude quando os jovens já estão contemplados em outras políticas setoriais como as de saúde, educação, trabalho, dentre outras, e entre a concepção de que as políticas da juventude devem focar apenas as açōes destinadas aos jovens em "situação de exclusão social" ou em condiçôes de "vulnerabilidade", mais próximas de áreas articuladas às demandas culturais, de tempo livre, de lazer e, principalmente, de ações que possibilitassem a real participação dos jovens, ampliando a esfera de sua cidadania.

Spósito e Corrochano (2005) sinalizam que esses programas podem trazer embutidas novas formas de dominação, obscurecidas pelo discurso da inserção social e da cidadania, com elementos que dizem respeito ao "protagonismo" juvenil e à mobilização dos jovens, mas que permanecem no campo do discurso que dissimula a inexistência de práticas inovadoras. Desse modo, é necessário que se problematize também o discurso sobre o protagonismo juvenil, presente nas políticas públicas de juventude, em especial nas de saúde e de educação. As ações de protagonismo juvenil, na atualidade, oscilam entre o foco sobre uma participação despolitizada dos jovens e a construção de um ativismo social conformista, ou, por outro lado, as mesmas fontes acabam indicando possibilidades para a construção da autonomia juvenil (ZIBAS; FERRETI; TARTUCE, 2006). Esse conceito pode trazer, veladas, estratégias de controle sobre os jovens, disfarçadas em açōes de participação e de empoderamento. Zibas, Ferreti e Tartuce (2006) apontam que as tentativas apressadas de tornar didáticos ou operacionais conceitos presentes em documentos oficiais podem acabar por produzir distorçôes que dificultam a 
compreensão crítica desses conceitos, por sua naturalização e transformação em recomendações simplificadas sobre o caminho a ser trilhado.

Esse fato pode reforçar a ideia de que as políticas de juventude são um espaço de intervenção pública transversal e periférico. Ao mesmo tempo, traz inflexões importantes que podem constituir novas arenas no âmbito da esfera pública, como lócus de disputa em torno dos modelos normativos que orientam as representações sobre a condição juvenil no país, bem como as expectativas de sua inserção no mundo adulto, apontadas por Spósito e Corrochano (2005).

No que se refere à perspectiva das políticas públicas de saúde, pode-se afirmar que essas políticas são, desde as primeiras reflexões, destinadas aos adolescentes e jovens, sendo importante considerar como marco a Constituição Federal de 1988 e as Leis Orgânicas da Saúde, que estabelecem a saúde como direito de todos e como dever do Estado. A partir daí, tem-se a implementação de ações programáticas destinadas a esse público, como o PROSAD - Programa Saúde do Adolescente, em 1989 (BRASIL, 1989), alvo de diversas críticas e dificuldades para sua implementação, avaliadas como limitadas, incipientes e pontuais (BURSTYN; RIBEIRO, 2005).

Outros programas do Ministério da Saúde lançados a partir daí trazem o foco tradicional dos riscos e ameaças que repercutem na saúde pelo fato de os indivíduos serem adolescentes e jovens, como se fossem esses momentos diferentes dos demais momentos da vida: as DST/HIV, a gravidez, as drogas, entre outros, estruturados nos tradicionais "pacotes de saúde" ofertados à população de forma geral (BRASIL, 2000c; 2000b; 2006). Outros documentos oficiais trazem orientações para os profissionais de saúde como forma de divulgar aspectos legais de proteção aos adolescentes e jovens, documento intitulado "Marco Legal", e para a organização dos serviços de saúde com vistas à educação permanente em saúde, objetivando qualificar os profissionais para o trabalho com adolescentes e jovens (BRASIL, 2002; 2005; 2005b; 2007). Além disso, esses documentos visam a privilegiar os adolescentes e jovens nas açóes de saúde, por serem uma população pouco frequente nos serviços de saúde, além do principal fato, centrado nos riscos dessa "fase da vida”. Também com a mesma distorção, frequente nas políticas de forma geral, no que se refere ao protagonismo juvenil, tem-se uma proposta do Ministério, lançada em 2000, de formar adolescentes promotores da saúde, sendo multiplicadores de ações classificadas como de promoção da saúde, mas que estão centradas na 
prevenção dos agravos prevalentes nessa população (BRASIL, 2000a). Aqui há mais um destaque importante, considerando-se que tais ações não são implementadas nem pelos profissionais de saúde, mas que são transferidas aos adolescentes como responsáveis por elas. Essa reflexão também foi apontada por Spósito et al. (2006), ao analisarem os programas de transferência de renda para jovens. Afirmam que esses programas trazem ações de mobilização social, não realizadas nem mesmo pelo Estado mas transferidas aos jovens como tarefa.

Desse modo, considerando as publicações oficiais de saúde, os adolescentes e jovens permanecem à margem da atenção à saúde com propostas de ações simplistas e reducionistas. No ano de 2007, as diretrizes para uma política de atenção integral à saúde dos adolescentes e jovens, na qual as açôes de saúde para esses sujeitos estão inseridas nos blocos de financiamento do Pacto pela Saúde e de Gestão, rompem com a constituição de um programa específico para a atenção a saúde desses, inserindo os adolescentes e jovens nas ações de rotina dos serviços de saúde (AMARANTE; SOARES, 2009).

Horta, Lage e Sena (2009) afirmam que, apesar de considerações teóricas sobre a importância do jovem como copartícipe na construção de políticas públicas no setor saúde, o jovem ainda é objeto dessas políticas por uma ótica de riscos e vulnerabilidade. Considera-se que os programas destinados a essa população têm baixa capacidade de induzir mudanças, ainda se concentrando num campo de ações programáticas pontuais que não avançam para o delineamento de uma política voltada para a saúde dos jovens.

Desse modo, é possível afirmar que, mesmo presentes na sociedade, a discussão sobre a juventude, as políticas públicas de forma geral e de saúde, em particular, ainda necessitam avançar para um diálogo mais amplo, ora setorializado, ora intersetorial, mas capaz de ver efetivamente os jovens nos espaços sociais de sua vida, atender a suas demandas e necessidades para além de um foco de problemas e riscos, compreendidos como sujeitos. É preciso que esse diálogo traga repercussões para a qualidade de vida desses jovens.

\section{A análise do processo saúde-doença na adolescência e juventude versus práticas de saúde}

A compreensão tradicional de saúde e doença fez com que, por muito tempo, a saúde fosse considerada como ausência de doença, sendo determinada biologicamente. Ao longo do século XX, com a evolução da construção social da 
saúde, instauram-se novas formas de compreensão do processo saúde-doença e de seus determinantes, remetendo ao entendimento da saúde como recurso para a vida e construído no cotidiano pelas pessoas, dentro de suas possibilidades. O processo saúde-doença é tido então como interdependente e socialmente determinado, sendo importante compreender a inserção social dos sujeitos para a elaboração de ações de saúde que levem em conta a vulnerabilidade.

Essa análise é fundamental quando se remete à saúde dos jovens. Para isso, é preciso ir além das associações com violência, desemprego, drogas, problemas sociais. São associações constantes e automáticas quando se pensa em adolescentes e jovens, apesar de não serem privilégio dessa faixa etária (ROCHA, 2005). Na área da saúde, a associação negativa a essa população não é diferente. A partir das publicações selecionadas neste estudo, foi possível apreender que os documentos oficiais ainda centram no tratamento de algum tipo de risco aos quais os jovens estariam expostos, com açóes de finalidade curativa de forma prevalente e também preventiva e que reforçam a concepção de adolescência como uma fase de riscos (RAUPP, 2005).

Compreender a inserção social possibilita análises e ações diferenciadas, quando se pensa a saúde dos jovens. O estudo de Nogueira et al. (2009), por exemplo, numa análise da distribuição espacial da gravidez, constatou que, nos conglomerados, concentram-se altas taxas de mães adolescentes, em associação com as piores condiçôes socioeconômicas, quadro parecido com o encontrado para o número de homicídios de adolescentes e de tráfico de drogas. O estudo salienta, ainda, que a perspectiva desse fenômeno não é unicausal, sendo importante considerar as relações sociais, a aceitação e o apoio das famílias, o planejamento da criança, a coabitação ou não com o parceiro e a presença de instrumentos públicos de saúde e educação para as mães e seus filhos como fundamentais para configurar o cenário de ocorrência da gravidez. Apontam a necessidade de compreender as categorias de adolescentes e gravidez na adolescência como categorias sócio-construídas em que o entendimento dos aspectos culturais e de fatores socioambientais que ocorrem no quadro da vulnerabilidade são fundamentais para as políticas que queiram atuar para alterar esse quadro, reforçando que não devem se pautar na perspectiva homogeneizante dessas categorias.

A compreensão do processo saúde-doença como socialmente determinado, atrelada a parcerias com a família, comunidade e autoridades, pode resultar em práticas de impacto no quadro de morbi-mortalidade dos jovens na atualidade 
em que as causas externas, em especial a violência, são marca importante. Nesse sentido, Priuli e Moraes (2007) consideram que são essas as medidas de sucesso para a mudança do quadro de $64,4 \%$ das mortes dos jovens de 15 a 29 anos no Brasil.

A necessidade de se ter espaços capazes de oportunizar aos jovens a análise de sua situação de saúde e a projeção desta para o futuro dentro de seu contexto de vida se faz fundamental. Assim, é possível compreender os determinantes que incidem favorecendo ou não o processo saúde-doença para além de uma perspectiva linear do risco, buscando criar espaços voltados para o favorecimento do acesso à informação e ao debate de forma dialógica com os jovens sobre os aspectos que envolvem a saúde. Essa perspectiva nos aponta para a importância de associação entre a categoria modo de vida e condição juvenil para a estruturação de ações de saúde que sejam efetivas. Atentar para as necessidades de saúde dos jovens para além das doenças sexualmente transmissíveis, da gravidez e das drogas, tão difundida nos documentos oficiais da saúde, mas com pouca organização e impacto na atenção à saúde desses, pode revelar caminhos possíveis para práticas mais eficazes que os coloquem em um espaço de sujeitos de seu processo saúde-doença (ORLANDI; TONELI, 2008; PINTO et al., 2007). Refletir sobre os projetos de vida, negociar as práticas de cuidado com a saúde numa perspectiva que leve em conta o contexto de vida e os recursos de acesso dos jovens, a vulnerabilidade, os direitos e as (im)possibilidades podem ser caminhos interessantes de abordagem que os considerem como cidadãos.

Vale destacar que a percepção sobre saúde, apontada por Garbin et al. (2009) em estudo com os próprios jovens, sinaliza para uma concepção holística e ecológica, inter-relacionada com outros fenômenos, numa perspectiva que vai além do foco dos programas e práticas atuais, e que precisa ser valorizada na relação com os jovens. Essa percepção se diferencia daquelas que têm norteado os programas e as práticas atuais que focalizam o risco numa perspectiva negativa e centrada na doença ao se pensar os jovens. Nesse ponto, os jovens sujeitos do estudo proposto por Garbin et al. (2009) se consideram saudáveis e apontam para uma percepção de saúde voltada para os aspectos estéticos do corpo, buscando manter certo padrão de beleza, ainda pouco explorada na relação do setor saúde com os jovens em seu cotidiano de vida.

Tem-se, com isso, a necessidade de se conhecer as especificidades locais na estruturação de ações, uma vez que há evidências da possibilidade de 
integração entre as possibilidades de risco e proteção na vida dos indivíduos e a necessidade de pesquisas contextuais, para que políticas públicas possam ser criadas e efetivadas dentro das mais diferentes comunidades jovens no Brasil (MORAIS; KOLLER, 2004). Desse modo, Chaise, Soares e Meneghel (2008) apontam que a análise da realidade em que os jovens vivem e a construção de práticas educativas e de promoção à saúde podem potencializar suas habilidades e atitudes em relação à vida, valorizando-os como sujeitos e norteando a prática dos profissionais de saúde.

A parceria com as comunidades locais, com os equipamentos sociais aos quais os jovens se vinculam, com os programas oriundos de diferentes setores, atrelada a um compromisso político, pode resultar em práticas de impacto na configuração do quadro de morbi-mortalidade atual, e que seja menos sombrio para os jovens. Também a informação para a cidadania, o fortalecimento da autoestima e a preparação para o trabalho com os jovens são revelados em estudo de Gomes et al. (2007) como importantes para a redução da violência no Brasil.

Desse modo, é possível desenvolver ações mais focadas na promoção da saúde, em especial na atenção primária, ao contrário das práticas de hoje, que, no que se refere à violência, se centram no atendimento às vítimas de agravos; no que se refere às doenças sexualmente transmissíveis, centram-se no tratamento e na prevenção e que, de forma geral, se limitam à queixa de um sintoma, instantaneamente medicalizado, e que em nada contribuem para o empoderamento dos jovens como sujeitos em seu processo saúde-doença. Sem contar, ainda, aqueles casos, até mesmo "desconsiderados" pelos serviços de saúde locais, por não se enquadrarem na oferta de ações, sendo referenciados para serviços especializados no atendimento dessa população ou em agravos específicos. O caminho deve ser traçado no sentido de superar as ações propostas atualmente, que têm o foco maior na redução dos riscos e no despreparo atribuído a essa fase, pouco ainda ao fortalecimento dos fatores protetores. Para uma ruptura dessa abordagem, fica revelada, então, a necessidade de se incorporarem os referenciais dos determinantes do processo saúde-doença na explicação dos condicionantes de morbi-mortalidade dos jovens, uma vez que a explicação linear do adoecimento não dá conta da complexidade que perpassa as necessidades e a amplitude da saúde dos jovens (HORTA; LAGE, SENA, 2009). Por fim, buscar caminhar na perspectiva trazida por Rocha, na qual: 
As ações voltadas para a população juvenil devem ser, então, mais proativas e menos reativas, de maneira que possamos romper círculos viciosos calcados no medo de possíveis descaminhos dos jovens. É preciso ouvir, planejar, agir e avaliar com os jovens, apostar em seu poder de criação, de compreensão de suas necessidades e de execução de propostas diferenciadas. Se olharmos com atenção para a juventude de hoje veremos não apenas a crítica ao modo de vida vigente, mas também a produção de soluções interessantes, com forte acento artístico cultural. Os grupos de jovens são inúmeros e diversos entre si, mas trazem em comum essa capacidade propositiva, questionadora e reflexiva. Expressam suas críticas e seus desejos em prosas, versos, melodias, traços, cores, gestos e olhares (ROCHA, 2005, p. 221).

\section{Considerações finais}

A realização do presente estudo contribuiu para ampliar o conhecimento acerca da temática de saúde dos adolescentes e jovens, possibilitando vislumbrar as necessidades de avanços nas políticas públicas voltadas a essa população.

A análise dos dados revelou a necessidade de a saúde se apropriar do conceito de juventude para a construção de sua política e das práticas gerenciais e assistenciais. Esse referencial já é apontado como aquele que vai ao encontro do campo da Saúde Coletiva, fundamental para a construção de ações para os jovens que sejam implicadas e coerentes com seu cotidiano, numa perspectiva de sujeitos sociais o que implica açôes para além das práticas atuais, descontínuas, pouco envolventes e pontuais. Também aponta a necessidade de que as políticas e programas definam a saúde dos jovens, ultrapassando o recorte setorial e busquem ações integradas com maior potencial para alterar o quadro de vulnerabilidades dos jovens. Os avanços nas políticas públicas direcionadas aos jovens devem caminhar na perspectiva de considerá-los como sujeitos sociais e de direitos e na compreensão do processo saúde-doença para além de riscos. Os dados permitem afirmar a impertinência de se trabalhar somente no campo de riscos e vulnerabilidades no que se refere à saúde dos jovens brasileiros.

Com esse recorte, com base nos documentos oficiais de saúde e de publicações nacionais sobre as políticas púbicas, no contexto brasileiro, tem-se um grande desafio lançado para a saúde. Para que as ações de saúde impliquem os jovens, faz-se necessária a aproximação do contexto de vida dos mesmos, do cotidiano de suas vidas nas quais as ações de saúde possam perpassar uma perspectiva positiva e a abertura para construçôes de ações coletivas, que levem em conta os determinantes da produção social da saúde. A Estratégia de Saúde da Família pode 
ser um dos caminhos para um passo favorável de aproximação com o cotidiano de vida da população de forma geral e, em particular, dos jovens. Aliado a isso, faz-se necessária a qualificação dos profissionais de saúde para que sejam sensibilizados e despertados para o olhar para os jovens, como autores e emancipadores de sua própria história, com grande potencial para parcerias e reflexões. O desafio da intersetorialidade fica também revelado para a implementação de práticas que possam atender às necessidades de saúde dos jovens, para além de necessidades de consumo de serviços de saúde. Como afirmam Ferrari, Thomson e Melchior (2006, p. 2.492). citando Peduzzi (2001):

a partir do momento em que os profissionais da estratégia reorganizam suas atividades, as necessidades e ações de saúde irão se corresponder, e não só os problemas de saúde determinarão as ações como também o modo de organização do serviço corresponderá às necessidades de saúde, contemplando a dupla dimensão, a individual e a coletiva, do processo de saúde doença ampliando o campo da atenção e do cuidado.

Esperamos que este estudo contribua na construção de conhecimento, assim como na elaboração de políticas públicas destinadas aos jovens, e que repercuta na assistência à saúde desses sujeitos que são coprodutores da sociedade.

\section{Referências}

AMARANTE, A.G.M.; SOARES, C.B.S. Políticas públicas de saúde voltadas à adolescência e à juventude no Brasil. In: BORGES, A.L.V.; FUJIMORI, E. (Org.). Enfermagem e a saúde do adolescente na atenção básica. Barueri: Manole, v. 1, p. 42-60, 2009.

BORGES, A.L.V.; FUJIMORI, E. Condiçōes de vida e saúde da população adolescente no Brasil. In: . (Org.). Enfermagem e a saúde do adolescente na atenção básica. Barueri: Manole, v. 1, p. 23-41.

BRASIL. Ministério da Saúde. Programa Saúde do Adolescente: bases programáticas. Brasília: Ministério da Saúde, 1989.

BRASIL. Ministério da Saúde. Secretaria de Assistência à saúde. Normas de Atenção Integral do Adolescente. Brasília: Ministério da Saúde, 1993.

BRASIL. Ministério da Saúde. Saúde e desenvolvimento da juventude brasileira: construindo uma agenda nacional. Brasília: Ministério da Saúde, 1999.

BRASIL. Ministério da Saúde. Adolescentes promotores da saúde: uma metodologia de capacitação. Brasília: Ministério da Saúde. 2000a.

BRASIL. Ministério da Saúde. Prevenir é sempre melhor - 99. Coordenação Nacional de DST e Aids. 1 ed., Brasília: Ministério da Saúde, 2000b. 

Técnica de Saúde do Adolescente e do Jovem. Brasília: Ministério da Saúde, 2000c. BRASIL. Ministério da Saúde. Secretaria de Políticas de Saúde. Área Técnica de Saúde do Adolescente e do jovem. A Saúde de adolescentes e jovens: uma metodologia de auto-aprendizagem para equipes de atenção básica de saúde: módulo avançado. Brasília: Ministério da Saúde. 2002.

BRASIL. Ministério da Saúde. Secretaria de Atenção à Saúde. Área de Saúde do Adolescente e do Jovem. Marco legal: saúde, um direito de adolescentes. Brasília: Ministério da Saúde, 2005.

BRASIL. Ministério da Saúde. Secretaria de Atenção à Saúde. Saúde integral de adolescentes e jovens: orientaçōes para a organização de serviços de saúde. Brasília: Ministério da Saúde, 2005b.

BRASIL. Ministério da Saúde. Secretaria de Atenção à Saúde. Departamento de Ações Programáticas Estratégicas. Marco teórico e referencial: saúde sexual e saúde reprodutiva de adolescentes e jovens. Brasília: Ministério da Saúde, 2006.

BRASIL. Ministério da Saúde. Secretaria de Atenção à Saúde. Departamento de Ações Programáticas Estratégicas. A saúde de adolescentes e jovens: uma metodologia de auto-aprendizagem para equipes de atenção básica de saúde. Módulo básico. Brasília: Ministério da Saúde, 2007.

BRASIL Ministério da Saúde. Fundação Oswaldo Cruz. Um olhar sobre o jovem no Brasil. Brasília: Ministério da Saúde, 2008.

BRITO, A.J.R. Consórcio Social da Juventude de São Paulo: tecendo considerações sobre as escolhas e as perspectivas de inserção no mundo do trabalho das juventudes. Imaginario, v. 11, n. 11, p. 161-187, dez. 2005.

BURSZTYN, I.; RIBEIRO, J.M. Avaliação participativa em programas de saúde: um modelo para o Programa de Saúde do Adolescente. Cad. saúde pública, Rio de Janeiro, v. 21, n. 2, p. 404-416, mar-abr, 2005.

CHAISE, F.O.; SOARES, S.A.; MENEGHEL, S.N. Estão nossos jovens doentes? Percepções de adolescentes em relação à saúde em dois municípios gaúchos. Physis: revista de saúde coletiva, Rio de Janeiro, v. 18, n. 4, p. 817-828, 2008.

CORREIA, A.C.P.; FERRIANI, M.G.C. A produção científica da enfermagem e as políticas de proteção à adolescência. Rev bras enferm, v.58, n. 4, jul-ago, 2005, p. 449-53.

DEBERT, G.G. A antropologia e o estudo dos grupos e das categorias de idade. In: BARROS, M.M.L. (Org.) Velhice ou terceira idade? Estudos antropológicos sobre idade, memória e política. 3 ed. Rio de Janeiro: FGV, 2003. p. 49-68.

FERRARI, R.A.P.; THOMSON, Z.; MELCHIOR, R. Atenção à saúde dos adolescentes: percepção dos médicos e enfermeiros das equipes da saúde da família. Cad. saúde pública, v. 22, n. 11, p. 2491-2495, nov. 2006. 
FERRETI, C.; ZIBAS, D.; TARTUCE, G. Protagonismo juvenil na literatura especializada e na reforma do ensino médio. Cadernos de pesquisa, v. 34, n. 122, p. 411-423, maio/ ago. 2004.

FOUCALT, M. Microfísica do poder. Tradução de Roberto Machado. 19ed. Rio de Janeiro, Graal, 2004.

GARBIN, C.A.S. et al. A saúde na percepção do adolescente. Physis: revista de saúde coletiva, v. 19, n. 1, p. 227-238, 2009.

GOMES, R. et al. Êxitos e limites na prevenção da violência: estudo de caso de nove experiências brasileiras. Ciência \& saúde coletiva, v. 11, sup, p. 1.291-1.302, 2007.

GROSSMAN, E.; CARDOSO, M.H.C. A. As Bases conceituais dos documentos oficiais de atenção à saúde do adolescente. Revista brasileira de crescimento e desenvolvimento humano, São Paulo, v. 7, n. 2, p. 1-11, 1997.

IBGE. Instituto Brasileiro de Geografia e Estatística. Dados populacionais 2007. Disponível em www.ibge.gov.br. Acesso em: jan. 2010.

HORTA, N.C.; LAGE, A.M.D.; SENA, R.R. Produção científica sobre políticas públicas direcionadas para jovens. Rev. enf. UERJ, v. 17, n. 4, p. 538-43, set-dez, 2009.

NOGUEIRA, M.J. et al. Análise da distribuição espacial da gravidez adolescente no Município de Belo Horizonte - MG. Rev. bras. epidemiol., v. 12, n. 3, p. 297-312, 2009.

NOVAES, R.; VANNUCHI, P (Org.). Juventude e sociedade. São Paulo: Fundação Perseu Abramo, 2004.

OLIVEIRA, A.P.G.; MILNITSKY-SAPIRO, C. Políticas públicas para adolescentes em vulnerabilidade social: abrigo e provisoriedade. Psicol. cienc. prof., v. 27, n. 4, p. 623-635, dez. 2007.

ORLANDI, R.; TONELI, M.J.F. Adolescência e paternidade: sobre os direitos de criar projetos e procriar. Psicol. estud., v. 13, n. 2, p. 317-326, 2008.

PEDUZZI, M. Equipe multiprofissional de saúde: conceito e tipologia. Revista de saúde pública, São Paulo, v. 35, n. 1, p. 103-109, 2001.

PERES, F.; ROSENBURG, C.P. Desvelando a concepção de adolescência/ adolescente presente no discurso da Saúde Pública. Saúde soc., v. 7, n. 1, p. 53-56, jan-jul. 1998.

PINTO, A.C. S. et al. Compreensão da pandemia de AIDS nos últimos 25 anos. DST: j bras doenças sex transm., v. 19, n. 1, p. 45-50, 2007.

PRIULI, R.M.A.; MORAES, M.S. Adolescentes em conflito com a lei. Ciênc. saúde coleti$v a$, v. 12, n. 5, p. 1.185-1.192, 2007.

RAUPP, L.; MILNITSKY-SAPIRO, C. Reflexões sobre concepções e práticas contemporâneas das políticas públicas para adolescentes: o caso da drogadição. Saúde soc., v. 14, n. 2, p. 60-68, ago. 2005 . 
ROCHA, M.C. Juventude: apostando no presente. Imaginario, v. 12, n. 12, p. 205-223, jun. 2006.

SPOSITO, M.P.; CARRANO, P.C. Juventude e políticas públicas no Brasil. Revista brasileira de educação, São Paulo, v. 24, p. 16-39, 2003.

SPOSITO, M.P. Trajetórias na construção de políticas públicas de juventude no Brasil. In: PAPA, Fernanda de C. (Org.). Políticas públicas: juventude em pauta. São Paulo: Cortez, 2003b. p. 57-75.

SPOSITO, M.P.; CORROCHANO, M.C. A face oculta da transferência de renda para jovens no Brasil. Tempo soc., v. 17, n. 2, p. 141-172, nov. 2005.

SPÓSITO, M.P.; CARVALHO E SILVA, H.H.; SOUZA, N.A. Juventude e poder local: um balanço de iniciativas públicas voltadas para jovens em municípios de regiōes metropolitanas. Rev. bras. educ., v. 11, n. 32, p. 238-257, ago, 2006.

VILLELA, W.V.; DORETO, D.T. Sobre a experiência sexual dos jovens. Cad. saúde pública, v. 22, n. 11, p. 2.467-2.472, nov. 2006.

ZIBAS, D.M.L.; FERRETTI, C.J.; TARTUCE, G.L.B.P. Micropolítica escolar e estratégias para o desenvolvimento do protagonismo juvenil. Cad. pesqui., v. 36, n. 127, p. 51-85, abr. 2006. 


\section{Abstract}

\section{An approach to adolescence and youth in Brazilian health politics: a review}

This paper aims to analyze the approach and concept of "adolescent" and "youth" commonly found in health-related official documents published by the Brazilian Ministry of Health, as well as the organization of the approach to health proposed for these subjects. Furthermore, an attempt was made to contrast, compare and relate the official documents with the experiments and research taken from selected publications, trying to propose strategies for the improvement of present health policies. The approach was explorative, descriptive and document-based, and the study was carried out through the review of official documents published by the Brazilian Ministry of Health and of papers available in previously selected scientific publications. The data were discussed, by means of the analysis of the contents and the structuring of three analytical categories, considering: the concept of adolescence and youth, the perspective of public policies for the youth and the analysis of the health-disease process in youth contrasted with health practices. The conclusion was that the health sector's approach is centered on the concept of adolescence under a perspective of risk, with little regard to youth, and that fact is reflected upon structured public policies. All the healthrelated publications analyzed clearly show the fragmented comprehension of the health-disease process, with little regard to an integral approach to the health of the youth. The evidences of this study point to the need of integrating health with other youth-oriented policies, maintaining the dialog with the youth-related academic production for the improvement of the measures aimed at that population and the incorporation of such references in the field of health.

> Key words: public policies; adolescence; youth; health-disease process; adolescent health; nursing. 